\title{
Anti-DR5 monoclonal antibody-mediated DTIC-loaded nanoparticles combining chemotherapy and immunotherapy for malignant melanoma: target formulation development and in vitro anticancer activity
}

This article was published in the following Dove Press journal:

International Journal of Nanomedicine

I4 September 201 I

Number of times this article has been viewed

\author{
Baoyue Ding ${ }^{1,2}$ \\ Xin Wu' \\ Wei Fan ${ }^{1,3}$ \\ Zhaoyong $\mathrm{Wu}^{4}$ \\ Jing $\mathrm{GaO}^{5}$ \\ Wei Zhang' \\ Lulu $\mathrm{Ma}^{5}$ \\ Wang Xiang' \\ Quangang Zhu' \\ Jiyong Liu' \\ Xueying Ding ${ }^{5}$ \\ Shen Gao'
}

'Department of Pharmaceutics, Changhai Hospital, Second Military Medical University, Shanghai, ${ }^{2}$ Department of Pharmaceutics, Medical College of Jiaxing University, Jiaxing, ${ }^{3}$ The 425th Hospital of PLA, Department of Pharmacy, Sanya, ${ }^{4}$ Department of Pharmaceutics, Jiaxing Maternal and Childcare Hospital, Jiaxing, ${ }^{5}$ Department of Pharmaceutics, School of Pharmacy, Second Military Medical University, Shanghai,

People's Republic of China

The first three authors contributed equally to this work.

Correspondence: Shen Gao

Department of Pharmaceutics, Changhai Hospital, Second Military Medical University,

Shanghai, People's Republic of China

$\mathrm{Tel}+862181873715$

Fax +862181873715

Email liullk@I26.com

Xueying Ding

Department of Pharmaceutics, School

of Pharmacy, Second Military Medical University,

Shanghai, People's Republic of China

Tel $+86218187 \quad 1293$

Fax +862181871293

Email dingxueying@I26.com
Background: The increased incidence of malignant melanoma in recent decades, along with its high mortality rate and pronounced resistance to therapy pose an enormous challenge. Novel therapeutic strategies, such as immunotherapy and targeted therapy, are urgently needed for melanoma. In this study, a new active targeting drug delivery system was constructed to combine chemotherapy and active specific immunotherapy.

Methods: The chemotherapeutic drug, dacarbazine (DTIC), that induces apoptosis through the intrinsic pathway which typically responds to severe DNA damage, was used as a model drug to prepare DTIC-loaded polylactic acid (PLA) nanoparticles (DTIC-NPs), which were covalently conjugated to a highly specific targeting functional TRAIL-receptor 2 (DR5) monoclonal antibody $(\mathrm{mAb})$ that can contribute directly to cancer cell apoptosis or growth inhibition through the extrinsic pathway.

Results: Our in vitro experiments demonstrated that DTIC-PLA-DR5 mAb nanoparticles (DTIC-NPs-DR5 mAb) are an active targeting drug delivery system which can specifically target DR5-overexpressing malignant melanoma cells and become efficiently internalized. Most strikingly, compared with conventional DTIC-NPs, DTIC-NPs-DR5 mAb showed significantly enhanced cytotoxicity and increased cell apoptosis in DR5-positive malignant melanoma cells.

Conclusion: The DTIC-NPs-DR $5 \mathrm{mAb}$ described in this paper might be a potential formulation for targeting chemotherapy and immunotherapy to DR5-overexpressing metastatic melanoma. Keywords: malignant melanoma, DR5 monoclonal antibodies, dacarbazine, apoptosis, chemoimmunotherapy, active targeting nanoparticles

\section{Introduction}

Malignant melanoma is the most aggressive form of skin cancer, causing the majority of skin cancer deaths. The past five decades have witnessed a steady and rapid rise in the incidence of malignant melanoma in developed countries. ${ }^{1}$ In the US, an estimated 68,700 new cases of melanoma occurred in 2009, with 8650 deaths from malignant melanoma. ${ }^{2}$ Despite a greater understanding of the risk factors as well as the genetic and epigenetic causes of melanoma, the death rate from melanoma continues to increase faster than the death rate for most other types of cancer. ${ }^{3}$ Common treatments for malignant melanoma involve a combination of therapies, including surgical removal, chemotherapy, and radiotherapy. However, at least one third of 
patients with early-stage melanoma will develop metastases, and the prognosis for patients with metastatic melanoma remains dismal. These patients have a median survival of approximately 6-8 months, and less than 5\% will survive for five years or more. ${ }^{4}$ Accumulated genetic, functional, and biochemical studies suggest that melanoma cells become "bullet proof" against a variety of chemotherapeutic drugs by exploiting their intrinsic resistance to apoptosis and survival pathways during progression of melanoma. ${ }^{5}$ To date, no agent has achieved a clinically meaningful prolongation of overall survival. ${ }^{6-8}$ Thus, novel therapeutic strategies for melanoma are still sought, and there is a critical need for the development of therapeutic agents that can target aberrant survival pathways in metastatic melanoma to improve the treatment of this disease. ${ }^{9,10}$

In recent years, new strategies for cancer treatment based on drug-loaded nanoparticulate formulations have emerged. Nanoparticles represent promising drug carriers, especially for specific transport of anticancer drugs to the tumor site, which can improve therapeutic efficacy and reduce systemic toxicity. ${ }^{11,12}$ Nanoparticles have high drug-loading efficiency, with minor drug leakage and good storage stability, and may circumvent multidrug resistance in cancer cells. ${ }^{13}$ Polylactic acid (PLA) nanoparticles have good biodegradability and compatibility, are regarded as safe drug vectors, are widely used in drug delivery, and have been widely studied as an intravenously injectable drug vector. ${ }^{14-17}$ Meanwhile, some nanodrugs based on PLA nanoparticles have received funding to be clinically studied and some have been approved by the FDA after clinical studies. ${ }^{18,19}$ Nanoparticles can be delivered to tumor tissues by the enhanced permeability and retention effect, ${ }^{20}$ ie, passive targeting. Moreover, their biodistribution and permeability in tissues can be controlled by their size and surface properties. ${ }^{21}$ To obtain better selectivity and to enhance the uptake of nanoparticles by tumor cells, nanoparticles are often functionalized with ligands, such as antibody fragments or peptides. By combining nanoparticles with the tumor-targeting properties of ligands, nanoparticles offer the promise of specific and efficient active targeting delivery to tumor cells. ${ }^{22-25}$ Monoclonal antibodies (mAb) offer great potential as drug-targeting ligands. ${ }^{26}$

Tumor necrosis factor-related apoptosis-inducing ligand (TRAIL), a member of the tumor necrosis factor superfamily, is a promising agent for cancer therapy because of its ability to induce apoptosis in a variety of human cancer cell lines, but not in most normal cells. ${ }^{27,28}$ TRAIL transmits an apoptotic signal via two death receptors, ie, TRAIL-receptor1 (DR4) and TRAIL-receptor2 (DR5). Although there are additional receptor proteins (TRAIL-receptor3, TRAIL-receptor4, and osteoprotegerin) that can bind to TRAIL, these receptors lack functional death domains and do not transmit the apoptotic signal. ${ }^{29}$ Agonistic mAb targeting TRAIL-R1 and TRAIL-R2 selectively exhibit potent antitumor activity in vivo, with better stability, a longer half-life, and less toxicity than TRAIL. ${ }^{30-33}$ Consequently, DR4 and DR5 appear to be an ideal target for both active and passive immunotherapy.

In this study, to overcome the limitations of the current therapy strategies, a new active targeting drug delivery system comprising dacarbazine (DTIC)-loaded PLA-DR5 mAb nanoparticles (DTIC-NPs-DR5 $\mathrm{mAb}$ ) was constructed to combine chemotherapy and active specific immunotherapy in an optimal manner. DTIC was used as the model drug to prepare DTIC-NPs, which were covalently conjugated with DR $5 \mathrm{mAb}$ by a two-step carbodiimide (EDC) method. We then evaluated the characterization of active targeting nanoparticles in detail, with DTIC loading efficiency and DR5 conjugation ratios determined and defined. The binding and uptake of fluorescently-labeled DR5 functionalized nanoparticles into malignant (A375) melanoma cells overexpressing the DR5 receptor, as well as a DR5 underexpressing $(\mathrm{NIH})$ fibroblast cell line, was determined using confocal microscopy and flow cytometry. Cytotoxicity and cellular apoptosis assays using these nanoparticles and appropriate controls for melanoma cells and normal fibroblasts were also studied. This study is expected to provide guidance regarding how best to combine DR5 mAb with existing cancer therapeutic agents to improve available treatment modalities for malignant melanoma and other cancer therapies. In this study, to overcome the limitations of the current therapy strategies, a new active targeting drug delivery system of DTIC-NPs-DR5 mAb was constructed to combine chemotherapy and active specific immunotherapy in an optimal manner.

\section{Materials and methods Materials}

PLA (molecular weight 3000) was obtained from Shandong Institute of Medical Instruments (Shangdong, China). Human serum albumin or 3-(4,5-dimethylthiazol-2-yl)-2, 5-diphenyl tetrazolium bromide (MTT) was purchased from Sigma Chemical Co (St Louis, MO). DTIC was purchased from Suzhou Lixin Pharmaceutical Co (Suzhou, China). Humanized anti-DR5 mAb was purchased from Santa Cruz Biotechnology Inc (Santa Cruz, CA). A micro bicinchoninic acid protein assay kit was obtained from Pierce Chemical Company (Fort Pierce, FL). The human A375 malignant melanoma cell line and mice fibroblast NIH cell line were 
maintained in the International Joint Cancer Institute, Second Military Medical University (Shanghai, China). Dulbecco's Modified Eagle's Medium and fetal bovine serum was purchased from Hyclone Co (Logan, UT). Dimethyl sulfoxide, dichloromethane, acetone, and methanol were purchased from China National Medicine Corporation Ltd (Shanghai, China). The other chemicals used in this work were all analytical pure grade and used as received.

\section{Preparation of antibody-modified nanoparticles}

The DTIC-NPs were prepared using the double emulsion (w/o/w) and solvent evaporation method with minor modification. ${ }^{34}$ Briefly, $100 \mu \mathrm{L}$ of an aqueous solution of DTIC (w1) was emulsified using a $1 \mathrm{~mL}$ mixture of methylene dichloride and acetone $(3: 2, \mathrm{v} / \mathrm{v})$ containing $10 \mathrm{mg}$ of PLA polymers by an ultrasonic processor $(100 \mathrm{~W}, 60$ seconds, Branson Sonicator ${ }^{\circledR} 450$ ) in an ice bath to form the first emulsion (w1/o). The w1/o emulsion was then poured into $4 \mathrm{~mL}$ of human serum albumin solution (w2, 1\%,w/v). This mixture was sonicated for 1 minute $(100 \mathrm{~W}, 30$ seconds $\times 2)$ to form a double emulsion (w1/o/w2). The w1/o/w2 double emulsion was then diluted in $30 \mathrm{~mL} 0.3 \%$ human serum albumin solution and stirred at room temperature for 4 hours to evaporate the organic phase. The resulting nanoparticles were purified and obtained by centrifugation at 16,000 rpm for 30 minutes (L-100XP, Beckman Coulter, Fullerton, CA) and washed three times before lyophilization (V2 K VirTis Inc, Gardiner, NY). The phycoerythrin (PE)-loaded PLA nanoparticles (PE-NPs) were prepared by the same method and blank PLA nanoparticles (PLA-NPs) were prepared according to the abovementioned method but omitting the DTIC.

\section{Conjugation of DR5 monoclonal antibodies to nanoparticles}

DR5 mAb conjugation was developed using the coupling strategy for DR5 mAb and PLA nanoparticles with EDC as the coupling agent. Briefly, $1 \mathrm{~mL}$ of PLA nanoparticle suspension ( $5 \mathrm{mg} / \mathrm{mL}, \mathrm{pH} 7.4$ ) was incubated with $50 \mu \mathrm{L}$ of $50 \mathrm{mg} / \mathrm{mL}$ EDC for 4 hours at room temperature with gentle stirring. After that, the DR5 mAb were added into the nanoparticle suspension and incubated for 4 hours. After the conjugation reaction, the DTIC-NPs-DR5 mAb were purified by centrifugation (L-100XP) at 14,000 $\mathrm{rpm} \times 30$ minutes and redispersed in phosphate-buffered solution. Finally, DTIC-NPs-DR5 mAb were washed with phosphate-buffered solution several times and lyophilized.

\section{Characterization of antibody-modified nanoparticles}

Freeze-dried nanoparticles were dispersed in deionized water $(\mathrm{pH}$ 7.0). Average size and zeta potential of the DTIC-NPs and DTIC-NPs-DR5 mAb were analyzed using a dynamic light-scattering detector (Zeta sizer ZS90, Malvern, Worcestershire, UK). At least three different batches were analyzed to give an average value and standard deviation for particle diameter and zeta potential. Morphological examination of DTIC-NPs-DR5 mAb was performed using transmission electron microscopy. Briefly, after the DTICNPs-DR5 $\mathrm{mAb}$ were lyophilized, the dried nanoparticles were resuspended with deionized water. Samples were prepared by placing one drop of dilute dispersion onto a copper grid coated with a carbon membrane. The surface morphology of the DTIC-NPs-DR5 mAb samples was then visualized by transmission electron microscopy (H600, Hitachi, Tokyo, Japan).

\section{Evaluation of drug contents}

The concentration of DTIC was determined by high-performance liquid chromatography (Hitachi D-2000). Chromatographic separations were performed on a reversed phase-C18 column $(4.6 \mathrm{~mm} \times 200 \mathrm{~mm}, 5 \mu \mathrm{m}$, Dikma analysis column). Methanol/water $(30 / 70, \mathrm{v} / \mathrm{v})$ was used as the eluent at a flow rate of $1 \mathrm{~mL} / \mathrm{min}$. The detection wavelength was $319 \mathrm{~nm}$. Drug loading and entrapment efficiency were determined as follows. Briefly, $10 \mathrm{mg}$ of DTIC-NPs were introduced into Eppendorf tubes and dissolved in $1 \mathrm{~mL}$ acetonitrile and diluted by $0.1 \mathrm{M}$ citric acid. Meanwhile, the amount of DTIC in the solution was determined by high-performance liquid chromatography. Drug loading and encapsulation efficiency of the drug-loaded nanoparticles were calculated according to equations (1) and (2):

$$
\begin{gathered}
\text { Drug loading }(\%)=\frac{\text { amount of the drug in NPs }}{\text { amount of the NPs }} \times 100 \% \\
\text { Encapsulation efficiency }(\%) \\
=\frac{\text { amount of the drug in NPs }}{\text { amount of the feeding drug }} \times 100 \%
\end{gathered}
$$

\section{In vitro release study}

The in vitro release profile of DTIC from DTIC-NPs-DR5 $\mathrm{mAb}$ was determined by measuring the residual amount of DTIC present in the nanoparticles. For that purpose, several $1 \mathrm{~mL}$ aliquots of the same DTIC-NPs-DR5 mAb suspension were diluted with phosphate-buffered solution ( $\mathrm{pH} 7.4$, final 
volume $20 \mathrm{~mL}$ ) in a capped centrifuge tube. The tubes were incubated at $37^{\circ} \mathrm{C}$ and shaken horizontally at 120 strokes/ minute. At specified time periods (1-168 hours), three tubes of each formulation were withdrawn and centrifuged at $16,000 \mathrm{rpm}$ and $4^{\circ} \mathrm{C}$ for 30 minutes (L-100XP) to obtain nanoparticle precipitation by centrifugal force. After removing the supernatant, the precipitation was washed twice with distilled water and lyophilized. The amounts of residual DTIC in the nanoparticles were determined by high-performance liquid chromatography using the same procedure as described above. The released drug was quantified and the cumulative release profile with time was demonstrated. The amount of drug released over time was expressed as a percentage of the initial drug load in the nanoparticles.

\section{Determination of DR5 monoclonal antibodies on nanoparticle surface}

PE-loaded nanoparticles conjugated with FITC-labeled DR5 mAb (PE-NPs-DR5 mAb-FITC) were redispersed in phosphate-buffered solution at $\mathrm{pH}$ 7.4. Localization of FITC and PE was observed using a Leica TCS SP2 ultraviolet-visible confocal spectral microscope. PE-NPs were run as a control and the images were analyzed using Leica confocal software.

A dispersion of PE-NPs-DR5 mAb-FITC was introduced directly into a flow cytometer and analyzed using a FACScan flow cytometer (Becton Dickinson, San Jose, CA) as described elsewhere. ${ }^{35}$ As a control, PE-NPs without FITClabeled DR5 mAb were also analyzed.

\section{Quantification of DR5 mAb conjugated with nanoparticles}

The amount of DR5 mAb bound onto the nanoparticle surface was quantified using the micro bicinchoninic acid assay method. Micro bicinchoninic acid working solution $1 \mathrm{~mL}$ was added to a $1 \mathrm{~mL}$ phosphate-buffered solution ( $\mathrm{pH} 7.4)$ dispersion of DTIC-NPs-DR5 mAb $(2.5 \mathrm{mg} / \mathrm{mL})$ and DTICNPs $(2.5 \mathrm{mg} / \mathrm{mL})$ as blank. After 60 minutes of incubation, the absorbance was measured at $570 \mathrm{~nm}$ using a microplate reader. The results were compared with a standard curve of DR5 mAb solution in phosphate-buffered solution ( $\mathrm{pH} 7.4$ ) ranging from $1 \mu \mathrm{g} / \mathrm{mL}$ to $40 \mu \mathrm{g} / \mathrm{mL}$.

\section{In vitro experiments}

Human malignant melanoma A375 cell lines and mice fibroblast NIH cell lines were cultivated in monolayers to $80 \%$ confluence in Dulbecco's modified Eagle's medium supplemented with $10 \%$ fetal bovine serum at $37^{\circ} \mathrm{C}$ in a humidified environment of $5 \% \mathrm{CO}_{2}$. The medium was replenished every other day and the cells were subcultured after reaching confluence.

To observe the binding ability and specificity of antibodymodified nanoparticles to DR5-overexpressing A375 cells and DR5-negative NIH cells, a $1 \times 10^{6}$ cell suspension was incubated with PE-NPs-DR5 mAb-FITC ( $1 \mathrm{mg} / \mathrm{mL})$ for 60 minutes at $37^{\circ} \mathrm{C}$, with untreated cells used as a negative control. To examine further the specificity of antibodymodified nanoparticles to A375, a $1 \times 10^{6}$ cell suspension was treated with $\mathrm{DR} 5 \mathrm{mAb}$ for 30 minutes at $37^{\circ} \mathrm{C}$, before incubation with $1 \mathrm{mg}$ PE-NPs-DR5 mAb-FITC in $1 \mathrm{~mL}$ culture medium for 60 minutes at $37^{\circ} \mathrm{C}$, the cells were then pelleted by centrifugation. Thereafter, the cells were washed and analyzed by FACScan flow cytometer.

\section{Cellular binding and uptake of antibody-modified nanoparticles}

Cellular binding and uptake of PE-NPs-DR5 mAb-FITC in DR5-overexpressing and DR5-negative cell lines were examined by laser scanning confocal microscopy. In brief, $5 \times 10^{5} \mathrm{~A} 375$ and $\mathrm{NIH}$ cells were incubated overnight in media at $37^{\circ} \mathrm{C}$ in each well of 24-well plates before incubation with the PE-NPs-DR5 mAb-FITC for varying times at $37^{\circ} \mathrm{C}$ (untreated cells were used as controls), and then washed three times with phosphate-buffered solution, followed by fixation with 4\% p-formaldehyde for 15 minutes. Afterwards, Hoechst 33342 (Invitrogen, Carlsbad, CA) was used to counterstain the nuclei of the cells. Finally, the cells were imaged using Leica TCS SP2 ultraviolet-visible confocal spectral microscopy, and the images were analyzed using Leica confocal software.

\section{In vitro cytotoxicity}

Cytotoxicity was analyzed using a Cell Titer 96 nonradioactive cell proliferation assay kit according to the manufacturer's protocol (Promega, Madison, WI) ${ }^{36}$ Briefly, A375 cells and NIH cells $\left(5 \times 10^{3}\right)$ were cultured for 24 hours before treatment. Cells were then treated with various concentrations of free DTIC, DR5 mAb, DTIC-NPs, NPs-DR5 mAb, DTIC$\mathrm{NPs}+\mathrm{DR} 5 \mathrm{mAb}$ and DTIC-NPs-DR $5 \mathrm{mAb}$ for 3 days at $37^{\circ} \mathrm{C}$ in a $\mathrm{CO}_{2}$ incubator. The concentrations of DTIC and DR5 $\mathrm{mAb}$ used in this assay were varied from $0.001-8 \mu \mathrm{g} / \mathrm{mL}$ and $0.0008-5.8 \mu \mathrm{g} / \mathrm{mL}$ (equivalent to PLA concentration of up to about $0.5 \mathrm{mg} / \mathrm{mL})$. NIH cells $\left(5 \times 10^{3}\right)$ were treated with drug-free PLA nanoparticles (PLA-NPs) and drug-free PLA-DR5 mAb nanoparticles (PLA-NPs-DR5 mAb) with different concentrations $(137.5-2200 \mu \mathrm{g} / \mathrm{mL})$ to evaluate 
the cytotoxicity of the drug delivery system. Then, $20 \mu \mathrm{L}$ of MTT reagent $5 \mathrm{mg} / \mathrm{mL}$ was added to each well, followed by $150 \mu \mathrm{L}$ of dimethyl sulfoxide to dissolve the crystal 4 hours later. The absorbance of each well was measured at $570 \mathrm{~nm}$ using a microplate reader. Viability of untreated cells was set at $100 \%$, and absorbance of wells with medium and without cells was set as zero. All of the results were from at least triplicate experiments.

\section{Detection of cell apoptosis}

A375 cells $\left(1 \times 10^{5}\right.$ cells/well $)$ were preincubated in 24-well plates and incubated at $37^{\circ} \mathrm{C}$ in a $5 \% \mathrm{CO}_{2}$ incubator for 24 hours after treatment with DTIC $64 \mu \mathrm{g} / \mathrm{mL}$. DR5 mAb $(46 \mu \mathrm{g} / \mathrm{mL})$ or DTIC-NPs, NPs-DR5 mAb, DTIC-NPs + DR5 $\mathrm{mAb}$ and DTIC-NPs-DR5 mAb were loaded with the same amount of DTIC and DR5 mAb (untreated cells were used as controls) for 72 hours. The cells were washed with $0.1 \mathrm{M}$ phosphate-buffered solution, trypsinized, and centrifuged. The cell pellet was then resuspended in $490 \mu \mathrm{L}$ of the cold binding buffer, and aliquots of $5 \mu \mathrm{L}$ of diluted Annexin V-FITC and propidium iodide solutions were added to the tubes containing $490 \mu \mathrm{L}$ of the A375 malignant melanoma cell suspensions. The mixtures were then vortexed for five seconds and kept for 10 minutes on ice in the dark. After the incubation, the cell samples were analyzed by FACScan flow cytometer. The tests were carried out in triplicate.

\section{Data analysis}

The data were presented as mean \pm standard deviation. Statistical significance was determined using the two-sample $t$-test and analysis of variance, with $P<0.05$ as the significance level.

\section{Results}

\section{Particle size, zeta potential, and morphology}

In the present study, nanoparticles were prepared from a PLA polymer, using a modified double emulsion solvent evaporation method. Because nanoparticle size is important for developing drug delivery strategies at specific sites in the body, smaller nanoparticles may be prone to minimal particle uptake by nontargeted cells, including premature clearance by the mononuclear phagocytic system. ${ }^{37}$ An orthogonal design was used to optimize the preparation technology on the basis of single factor evaluation. Optimal concentrations for preparation of the nanoparticles were $10 \mathrm{mg} / \mathrm{mL}$ for PLA and $3 \mathrm{mg} / \mathrm{mL}$ for DTIC. The methylene dichloride:acetone ratio was $3: 2(\mathrm{v} / \mathrm{v})$, the concentration of human serum albumin was $1 \%$, and the volume ratio of $\mathrm{o} / \mathrm{w}$ was $1 / 10(\mathrm{v} / \mathrm{v})$.

The resulting DTIC-NPs were sized at $152.2 \pm 5.7 \mathrm{~nm}$ $(n=6)$, with a relatively monodispersed size (polydispersity index $<0.3$, Table 1 and Figure $1 \mathrm{~A}$ ), which was not much larger than for the drug-free nanoparticles $(138.0 \pm 3.6 \mathrm{~nm})$. However, there was an approximately $20 \mathrm{~nm}$ increase in the particle size of DTIC-NPs-DR5 mAb $(174.0 \pm 4.1 \mathrm{~nm})$ as compared with DTIC nanoparticles, presumably owing to the presence of DR5 $\mathrm{mAb}$ on the nanoparticle surface. The mean zeta potential of the DTIC-NPs was $-30.1 \pm 1.9 \mathrm{mV}(\mathrm{n}=6)$, whereas the mean zeta potential of the DTIC-NPs-DR $5 \mathrm{mAb}$ was $-34.6 \pm 2.3 \mathrm{mV}(\mathrm{n}=6$, Table 1 and Figure1B). It was further demonstrated that the increase in zeta potential may be attributed to the presence of DR $5 \mathrm{mAb}$ on the nanoparticle surface. As shown in Figure 1C, the dried nanoparticles were easily resuspended and well dispersed in water or phosphatebuffered solution. From Figure 1D and E, we could see that the targeted modified nanoparticles have the same spherical shape without any adhesion or aggregation, indicating that the nanoparticles were stable during the mAb conjugation process on the surface of the nanoparticles.

\section{Evaluation of drug contents}

We optimized the study formulations to control the size of nanoparticles as described above. Drug content also plays a critical role in targeted drug delivery. To obtain the large drug loading required to meet therapeutic needs, a high concentration of DTIC (about $3 \mathrm{mg} / \mathrm{mL}$, DTIC solubility about $4 \mathrm{mg} / \mathrm{mL}$ ) was chosen as the concentration for the inner water phase. DTICNPs with a drug loading of $17.8 \pm 0.8 \mu \mathrm{g} / \mathrm{mg}(\mathrm{n}=3)$ and an encapsulation efficiency of $71.7 \% \pm 2.5 \%(n=3)$ were used in subsequent experiments unless otherwise stated.

\section{In vitro release study}

The release profile in vitro was evaluated. A sustained release pattern was visible when DTIC was released from DTIC-DR5 mAb nanoparticles, as shown in Figure 2. The release behavior of DTIC from the polymer matrix showed a biphasic pattern characterized by a burst release in the first

Table I The particle size and zeta potential of NPs

\begin{tabular}{llll}
\hline & $\begin{array}{l}\text { Drug-free } \\
\text { NPs }\end{array}$ & DTIC-NPs & $\begin{array}{l}\text { DTIC-NPs- } \\
\text { DR5 mAb }\end{array}$ \\
\hline Size & $138.0 \pm 3.6 \mathrm{~nm}$ & $152.2 \pm 5.7 \mathrm{~nm}$ & $174.0 \pm 4.1 \mathrm{~nm}$ \\
Zeta potential & $-22.6 \pm 2.6 \mathrm{mV}$ & $-30.1 \pm 1.9 \mathrm{mV}$ & $-34.6 \pm 2.3 \mathrm{mV}$ \\
\hline
\end{tabular}

Note: Data are expressed as the mean \pm SD $(n=6)$.

Abbreviations: DTIC, dacarbazine; mAb, monoclonal antibody; NPs, nanoparticles; $\mathrm{SD}$, standard deviation. 
A

Size distribution by intensity

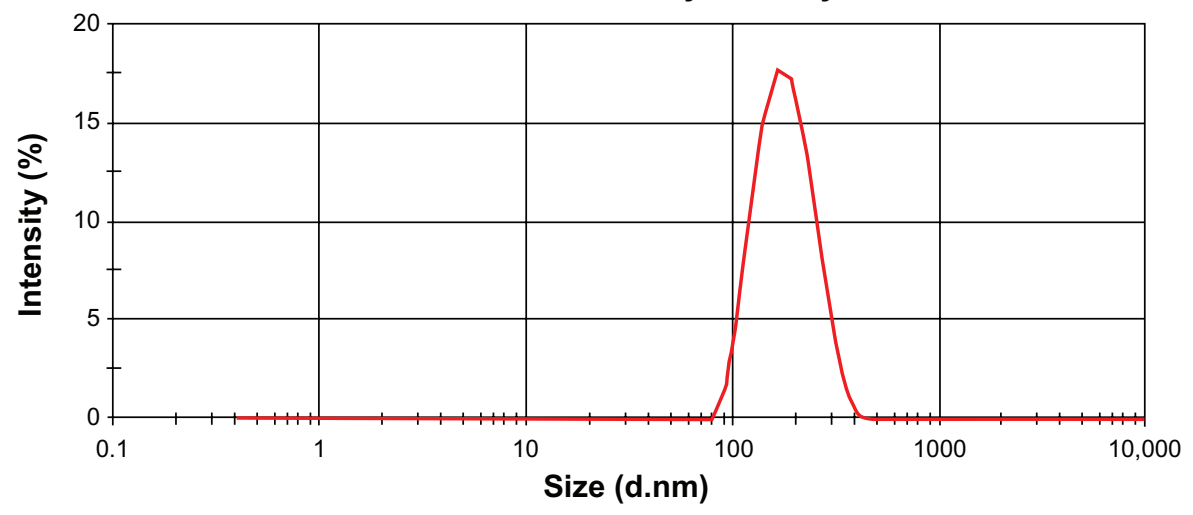

B

Zeta potential distribution
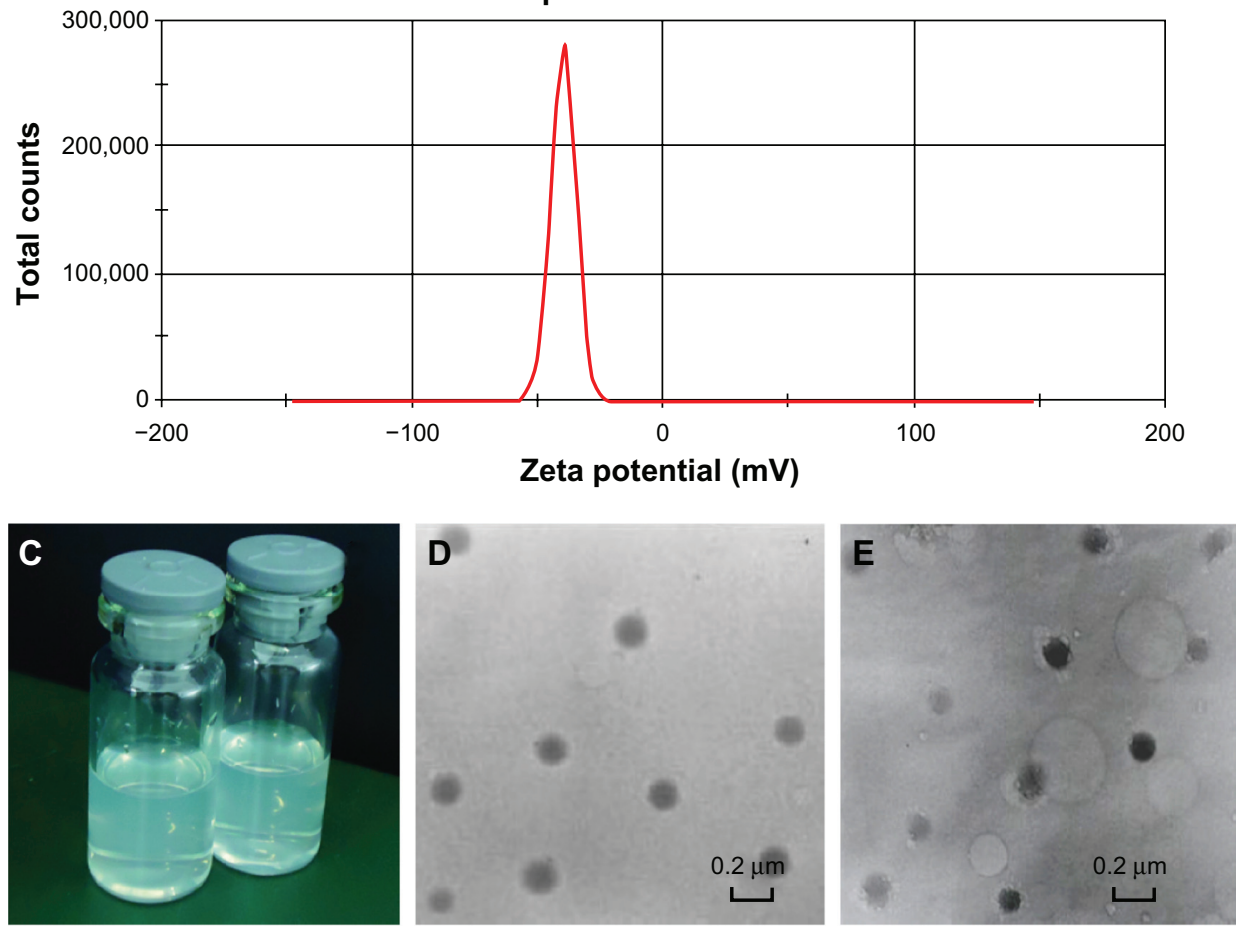

Figure I Characterization of nanoparticles. (A) Size distribution spectrum of DTIC-NPs - DR5 mAb determined by laser diffraction size detector. (B) Zeta potential of DTIC-NPs-DR5 mAb determined by laser diffraction zeta detector. (C) Image of the NPs dispersed in water or phosphate-buffered solution. (D and E) Morphology of DTIC-NPs and DTIC-NPs - DR5 mAb determined by TEM.

Abbreviations: DTIC, dacarbazine; mAb, monoclonal antibody; NPs, nanoparticles; TEM, transmission electron microscopy.

4 hours, which can be ascribed to the drug being located in or close to the nanoparticle surface, followed by a slower and continuous release. About $45 \%$ of the DTIC was released from the nanoparticles within 24 hours, and cumulative release was up to $80 \%$ at 72 hours. After that, a slower release rate could be observed, and nearly $90 \%$ DTIC was released in 7 days.

\section{Determination of DR5 monoclonal antibodies on nanoparticle surface}

Binding of DR5 $\mathrm{mAb}$ to the nanoparticle surface was evaluated by laser scanning confocal microscopy (Figure 3 ). The
FITC-labeled DR5 mAb-modified PE nanoparticles showed both red fluorescence (Figure 3B, represents the nanoparticles) and green fluorescence (Figure 3C, represents the DR5 mAb), and merged red/green fluorescence (Figure 3D) indicates that the nanoparticles were successfully coupled with DR5 mAb. In contrast, nanoparticles without mAb only showed red fluorescence (Figure 3A).

The conjugation of DR5 mAb to the nanoparticle surface was also confirmed by flow cytometry. As shown in density plots (Figure 3E and F), unlike the nanoparticles without antibodies, the antibody-modified nanoparticles showed green 


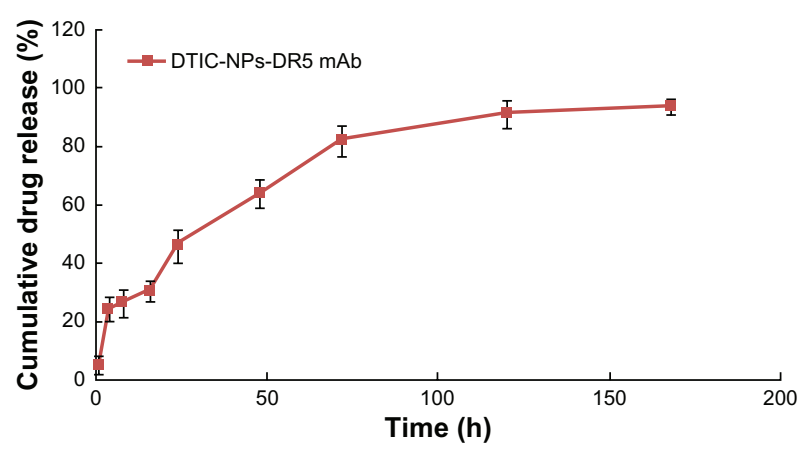

Figure 2 In vitro cumulative release profile of DTIC from DTIC-NPs-DR5 mAb in phosphate-buffered solution $\left(\mathrm{pH} \mathrm{7.4)}\right.$ at $37^{\circ} \mathrm{C}$.

Abbreviations: DTIC, dacarbazine; mAb, monoclonal antibody; NPs, nanoparticles.

fluorescence, indicating that nearly all nanoparticles were coupled with DR5 mAb through the conjugation reaction, and that the population of antibody-modified nanoparticles was rather homogeneous. A shift of FITC fluorescence intensity could be seen for antibody-modified nanoparticles (light green line) in comparison with nanoparticles without $\mathrm{mAb}$ (dark green line), indicating the presence of FITC-labeled DR5 mAb on the surface of the nanoparticles (Figure 3G).

The protein assay was used to quantify the amount of bound DR5 $\mathrm{mAb}$ on the nanoparticle surface. Because this assay cannot distinguish bound DR5 $\mathrm{mAb}$ from human serum albumin on the surface of nanoparticles, DTIC-NPs were run as a control. According to the protein assay, the amount of conjugated DR $5 \mathrm{mAb}$ on the antibody-modified nanoparticles was shown to be approximately $12.8 \pm 2.4 \mu \mathrm{g}$ DR $5 \mathrm{mAb} / \mathrm{mg}$ nanoparticles $(n=4)$.

\section{Recognition and binding properties of antibody-modified nanoparticles}

That the biological recognition activity of the targeting ligand is not destroyed in the conjugation procedure is key to the antibody-modified nanoparticles targeting the desired cell. We utilized flow cytometry to confirm the recognition properties of

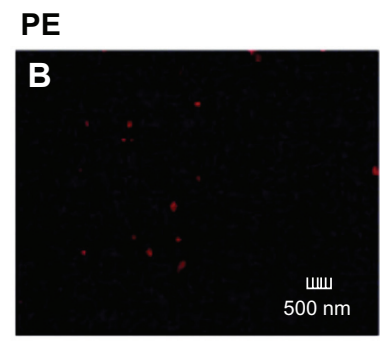

FITC
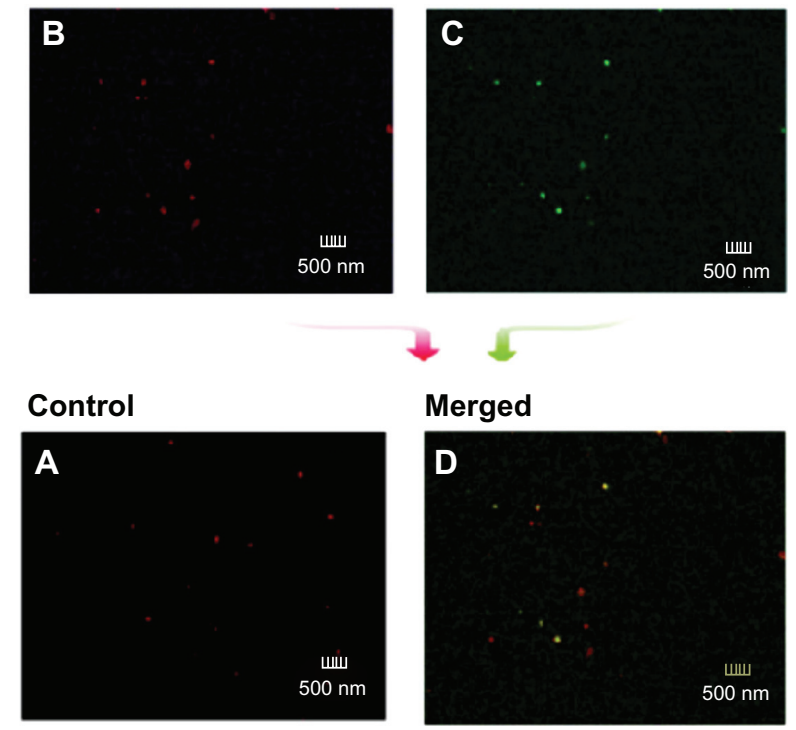

\section{Merged}
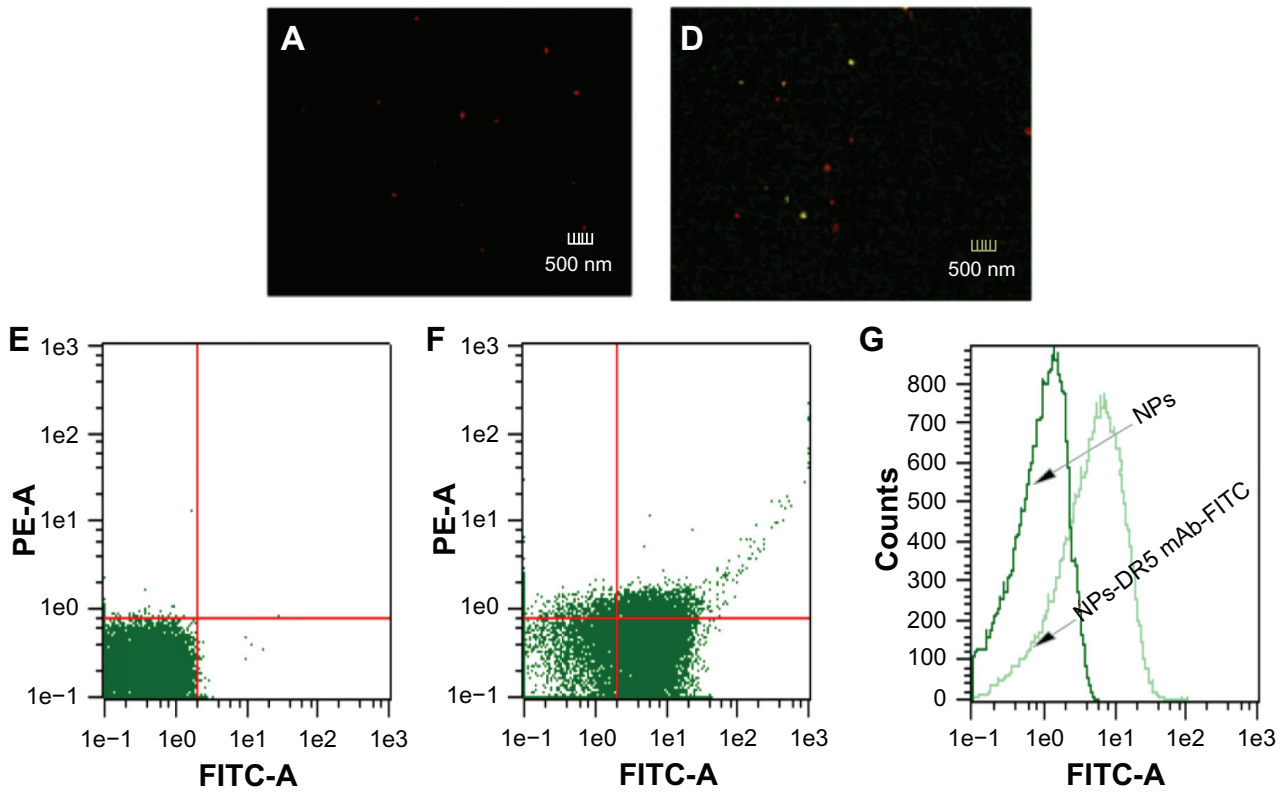

Figure 3 Determination of DR5 mAb on the surface of nanoparticles by flow cytometric analysis and confocal microscopy. (A) Control sample of nanoparticles. (B and C) Red and green fluorescence images of FITC-labeled DR5 mAb-modified PE-NPs by confocal microscopy. (D) Merged fluorescence image of FITC-labeled DR5 mAb-modified PE-NPs. (E and F) Density plots with or without NPs. (G) Fluorescence intensity of the NPs with or without antibody modification.

Abbreviations: DTIC, dacarbazine; mAb, monoclonal antibody; NPs, nanoparticles; PE, phycoerythrin; FITC, fluorescein isothiocyanate. 
PE-NPs-DR5 mAb-FITC for DR5. As shown in Figure 4A and $\mathrm{B}$, in contrast with NIH cells, PE-NPs-DR5 mAb-FITC-treated A375 cells had an apparent rightward shift of the fluorescence in the histogram compared with untreated cells, which indicated that DR5 antibody-modified nanoparticles possess a potent binding affinity for DR5-overexpressing A375 cells, but nearly no binding affinity for DR5-negative NIH cells (the slight fluorescence detected might have been caused by only a few nanoparticles being internalized into the cells by endocytosis or phagocytosis). In order to demonstrate further the specificity of the interaction of DTIC-NPs-DR5 mAb with the targeted cells, a competitive assay was performed using free DR5 mAb. As shown in Figure 4C, unlike the obviously fluorescent rightward shift of cells not pretreated with DR5 mAb, the rightward shift of the fluorescence in the histogram of cells pretreated with DR5 antibodies compared with untreated cells was slight, indicating that binding of DTIC-NPs-DR5 mAb to A375 cells was competitively inhibited by DR5 mAb, which demonstrates that the DTIC-NPs-DR5 mAb were internalized mainly by a ligand-mediated mechanism.

The flow cytometry results demonstrated that DR5 mAb were effectively conjugated to the nanoparticle surface with preserved biological activity during the process of covalent conjugation.

\section{Cellular binding and uptake of antibody-modified nanoparticles}

Confocal microscopy was used to confirm cellular uptake efficiency and intracellular distribution of the antibodymodified nanoparticles. Internalization of PE-DR5 mAb-FITC nanoparticles would lead to localized green FITC staining in the cytoplasm. After incubation with PE-DR5 mAb nanoparticles for different times, FITC and PE fluorescence was detected only on the A375 cell surface after 5 minutes of incubation. After a 30-minute incubation, FITC fluorescence and PE fluorescence were detected in the cytoplasm of all cells, and when incubated for 60 minutes, most of the PE nanoparticles were uptaken into the cells (Figure 5A). In contrast, when incubated with DR5-negative NIH cells for 1 hour (Figure 5B), no significant FITC fluorescence was detected, which is consistent with the above result for cellular binding. In the case of DR5 mAb nanoparticles, ligand-receptor recognition could help to increase internalization of the nanoparticles.

\section{In vitro cytotoxicity assays}

The in vitro cytotoxicity of the nanoparticles was tested using an MTT assay in NIH cells treated with increasing doses of PLA nanoparticles and DTIC-NPs-DR5 mAb which did not encapsulate DTIC. The nanoparticles were found to be nontoxic at each of the tested concentrations. We did not observe a significant difference in the toxicity of DTIC-NPs and DTICNPs-DR5 mAb, although there was a slight reduction in cell viability at higher concentrations. Average cell viability ranged from $80.1 \% \pm 3.9 \%$ to $93.5 \% \pm 2.4 \%(n=3)$ of control viability at the concentrations studied, suggesting that DTIC-NPs-DR5 $\mathrm{mAb}$ may be used as a target carrier (Figure 6).

The cytotoxic activity of DTIC-NPs-DR5 mAb against A375 and NIH cells was evaluated by MTT assay (untreated A375 or NIH cells were used as controls). As shown in Figure 7, A375 cells, which express high levels of DR5, were most sensitive to DTIC-NPs-DR5 mAb. However, the DR5-negative NIH cells were much less sensitive to DTIC-

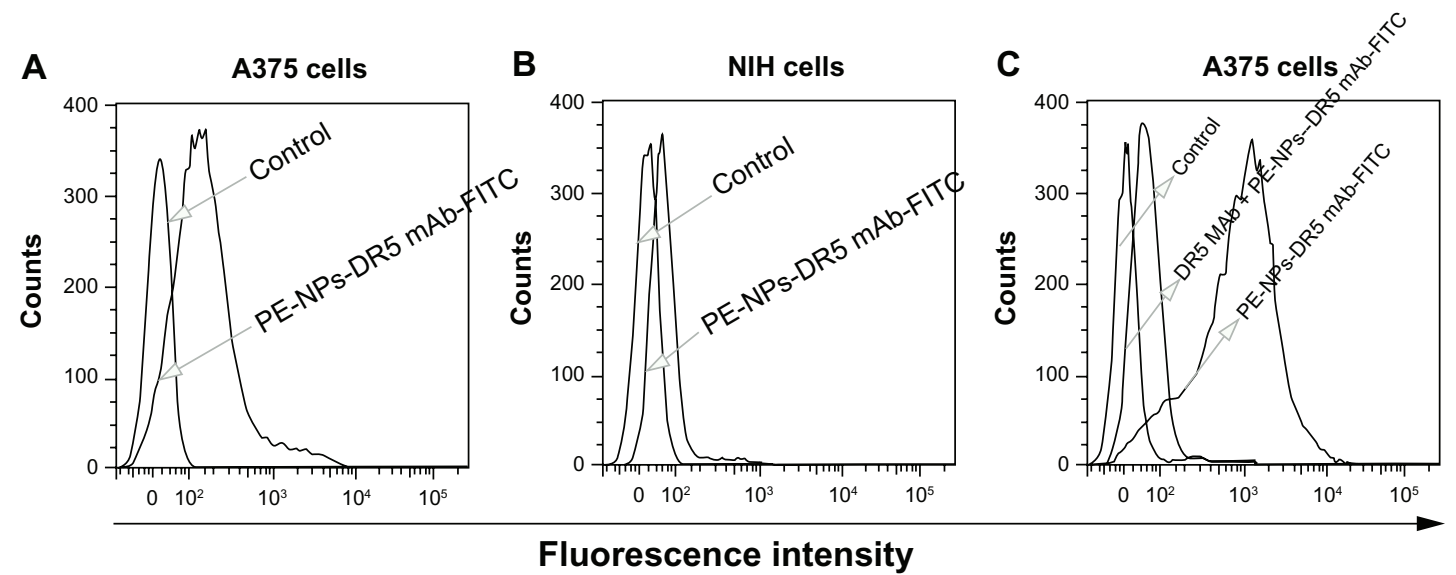

Figure 4 (A and B) Fluorescence intensity histogram of A375 cells and NIH cells treated by PE-NPs-DR5 mAb-FITC, untreated cells were used as negative control. (C) Fluorescence intensity histogram of A375 cells treated by DR5 mAb before the adding of PE-NPs-DR5 mAb-FITC, untreated cells and cells not pretreated with DR5 mAb were used as negative and positive controls, respectively.

Abbreviations: DTIC, dacarbazine; mAb, monoclonal antibody; NPs, nanoparticles; PE, phycoerythrin; FITC, fluorescein isothiocyanate. 


\section{A}

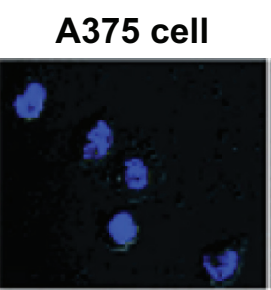

\section{FITC-mAb}

PE

Merge
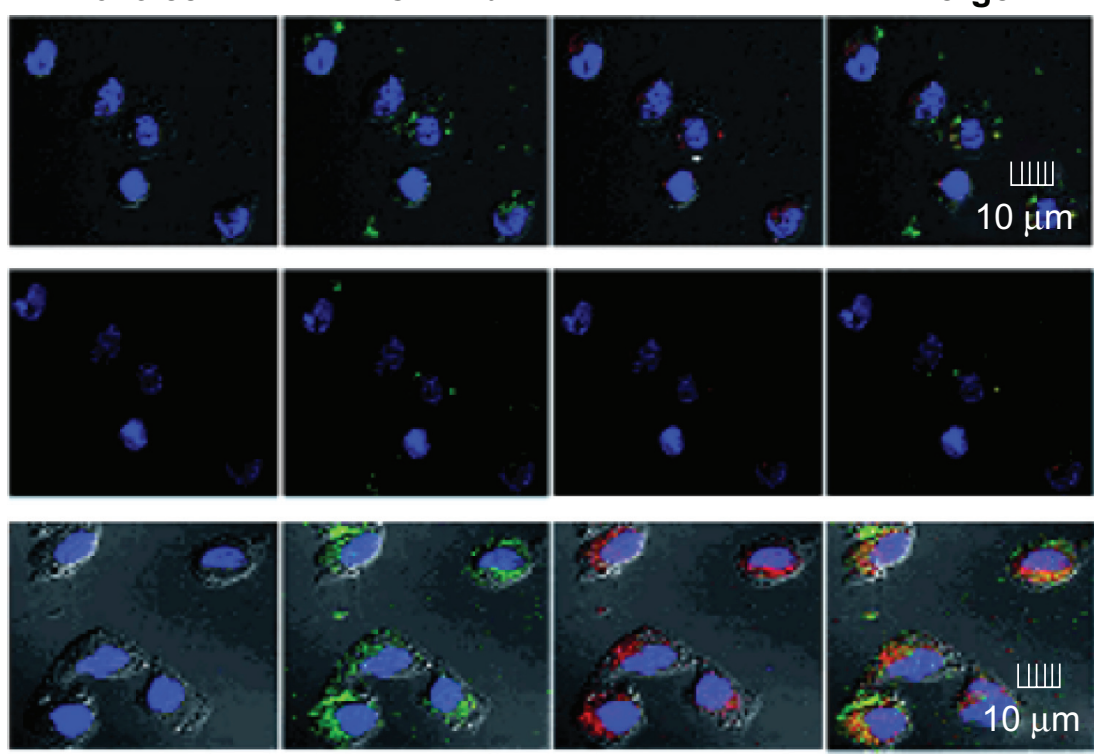

$30 \mathrm{~min}$

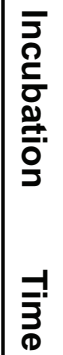
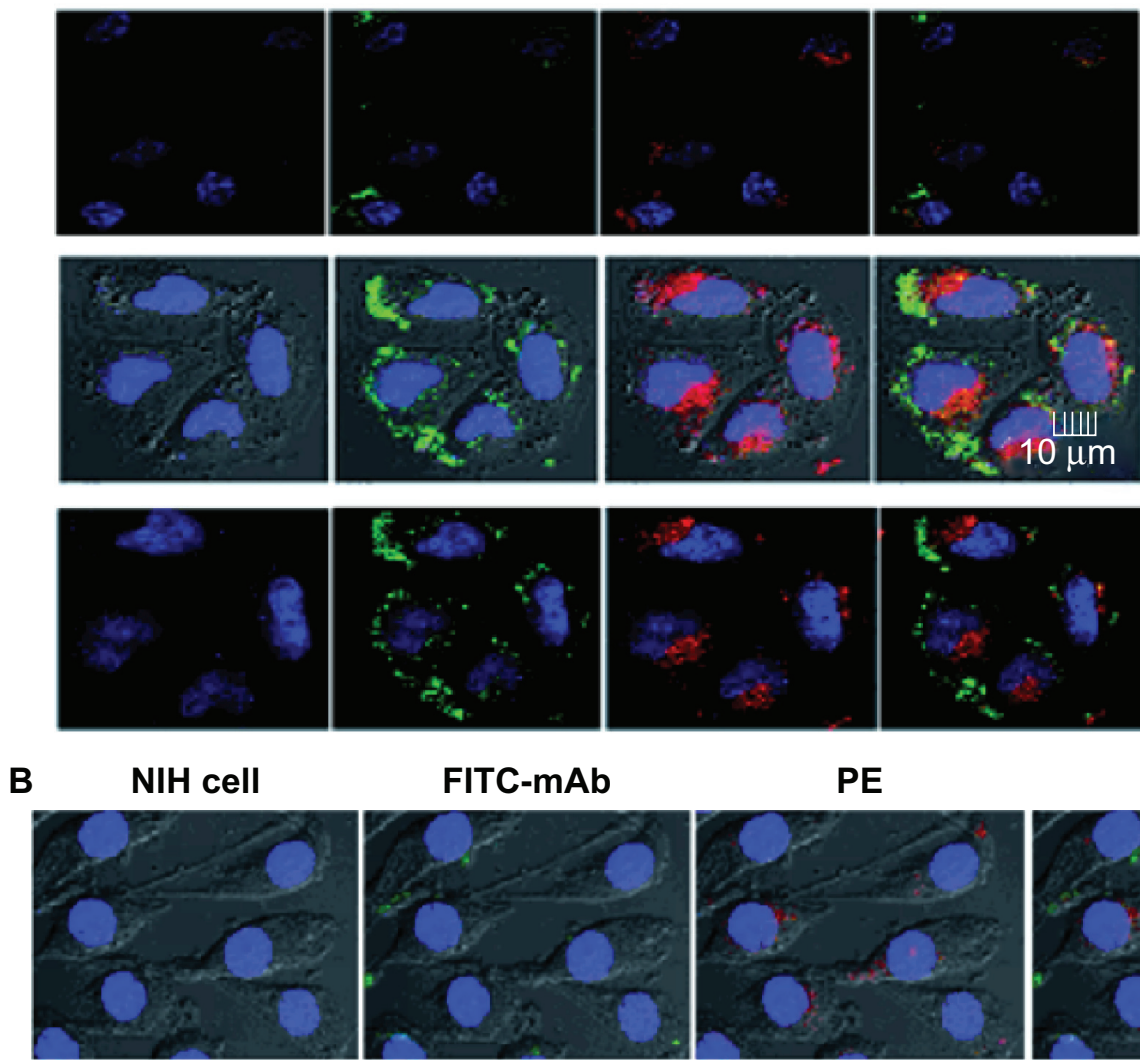

FITC-mAb

PE
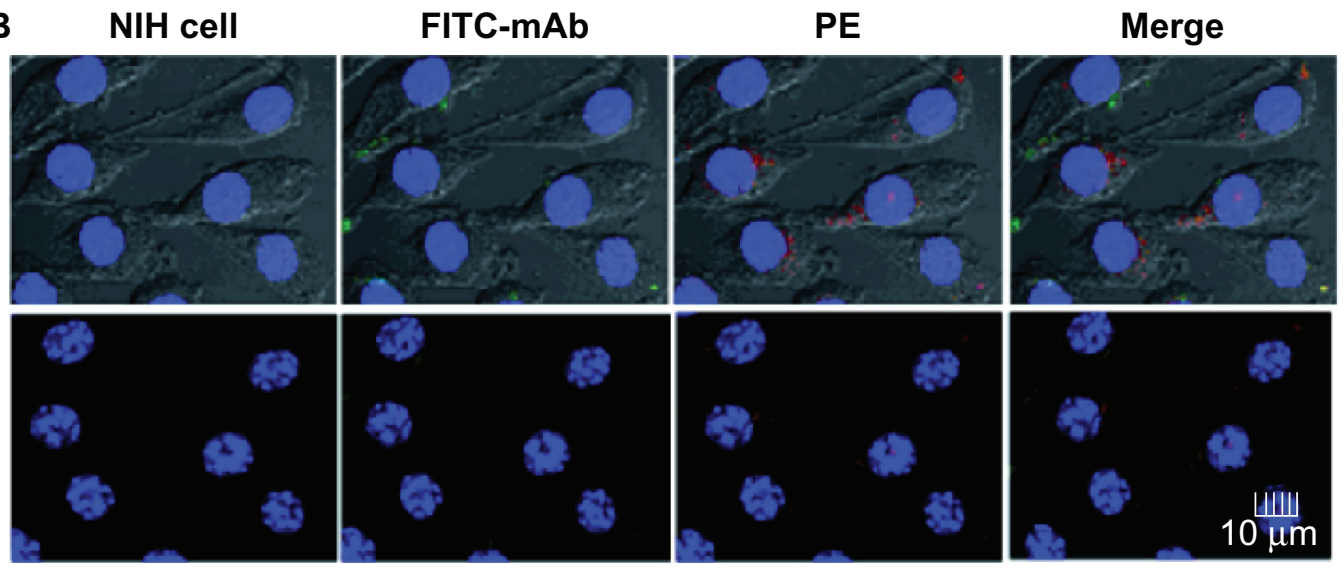

Figure 5 Binding and uptake of antibody modified nanoparticles. Binding and uptake analysis of PE-NPs-DR5 mAb-FITC were taken by confocal laser scanning microscopy. (A) A375 cells, with an incubation time of 5 minutes, 30 minutes, and I hour, (B) NIH cells had an incubation time of I hour. Cells were imaged by Leica TCS SP2 ultravioletvisible confocal spectral microscope and the images were analyzed by Leica confocal software.

Abbreviations: mAb, monoclonal antibody; NPs, nanoparticles; PE, phycoerythrin; FITC, fluorescein isothiocyanate. 


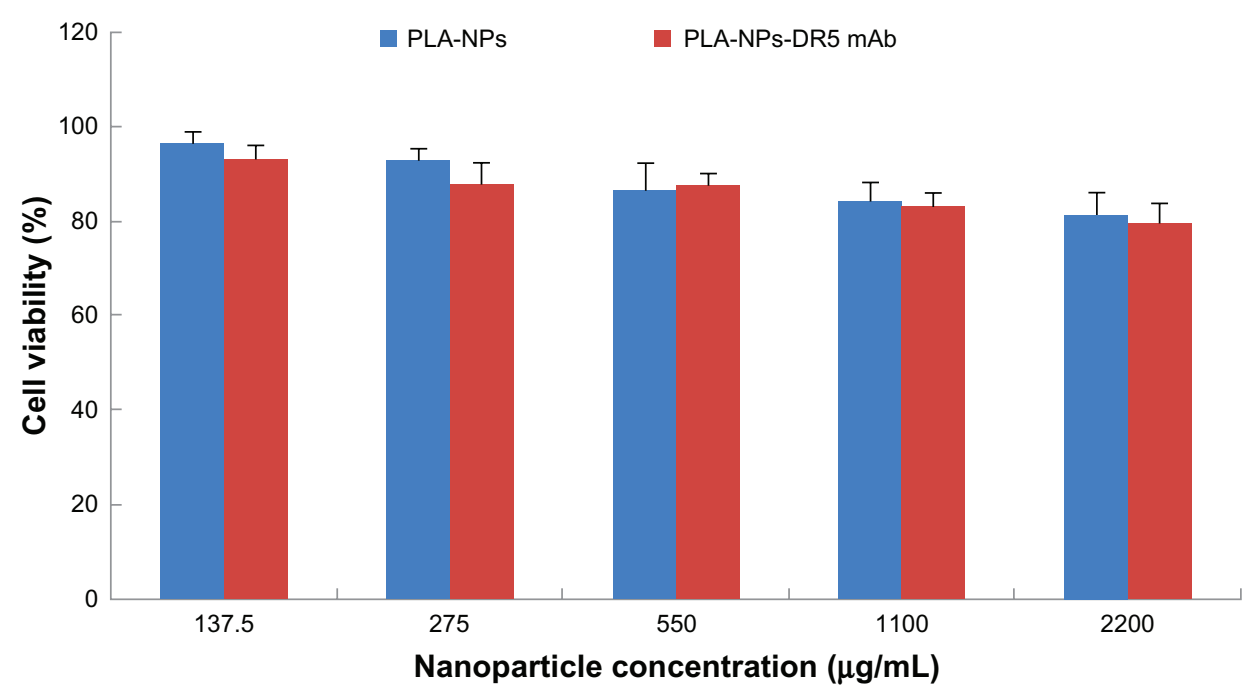

Figure 6 Cytotoxicity of PLA-NPs and PLA-NPs-DR5 mAb in NIH cells. The cells were incubated using different concentrations of NPs in the range from I $37.5 \mu \mathrm{g} / \mathrm{mL}$ to $2200 \mu \mathrm{g} / \mathrm{mL}$ for a time period of 24 hours (mean \pm standard deviation; $\mathrm{n}=5$ ).

Abbreviations: mAb, monoclonal antibody; NPs, nanoparticles; PE, phycoerythrin; FITC, fluorescein isothiocyanate; PLA, polylactic acid.

NPs-DR5 mAb. Similar results were obtained when the two cell lines were incubated with drug-free DR5 $\mathrm{mAb}$ nanoparticles, suggesting that the binding ability and specificity of DTIC-NPs-DR $5 \mathrm{mAb}$ and NPs-DR5 mAb for DR5 were critical for induction of cytotoxicity (Figure 8). It was clearly shown that DTIC-NPs-DR5 mAb were more cytotoxic to A375 cells when compared with DTIC, DR5 mAb, DTIC nanoparticles, NPs-DR5 mAb and DTIC-NPs + DR5 mAb. Incubation of the cells with free DTIC contributed to a smaller reduction in cell viability compared with the same concentration of drug provided by PLA nanoparticles. It might be related to the enhanced stability and improved cellular uptake of DTIC encapsulated by nanoparticles, which could also enable sustained chemotherapy. A mixture of DTICNPs and free mAb showed increased cytotoxicity compared with free DTIC, free mAb, and DTIC nanoparticles, which might be because DTIC and DR5 $\mathrm{mAb}$ are able to induce cancer cell apoptosis through the intrinsic pathway and extrinsic pathway, respectively. However, a mixture of DTIC nanoparticles with free $\mathrm{mAb}$ in the same amount as that conjugated to DTIC-DR5 mAb nanoparticles showed lower cytotoxic activity against A375 cells than DTIC-DR5 mAb

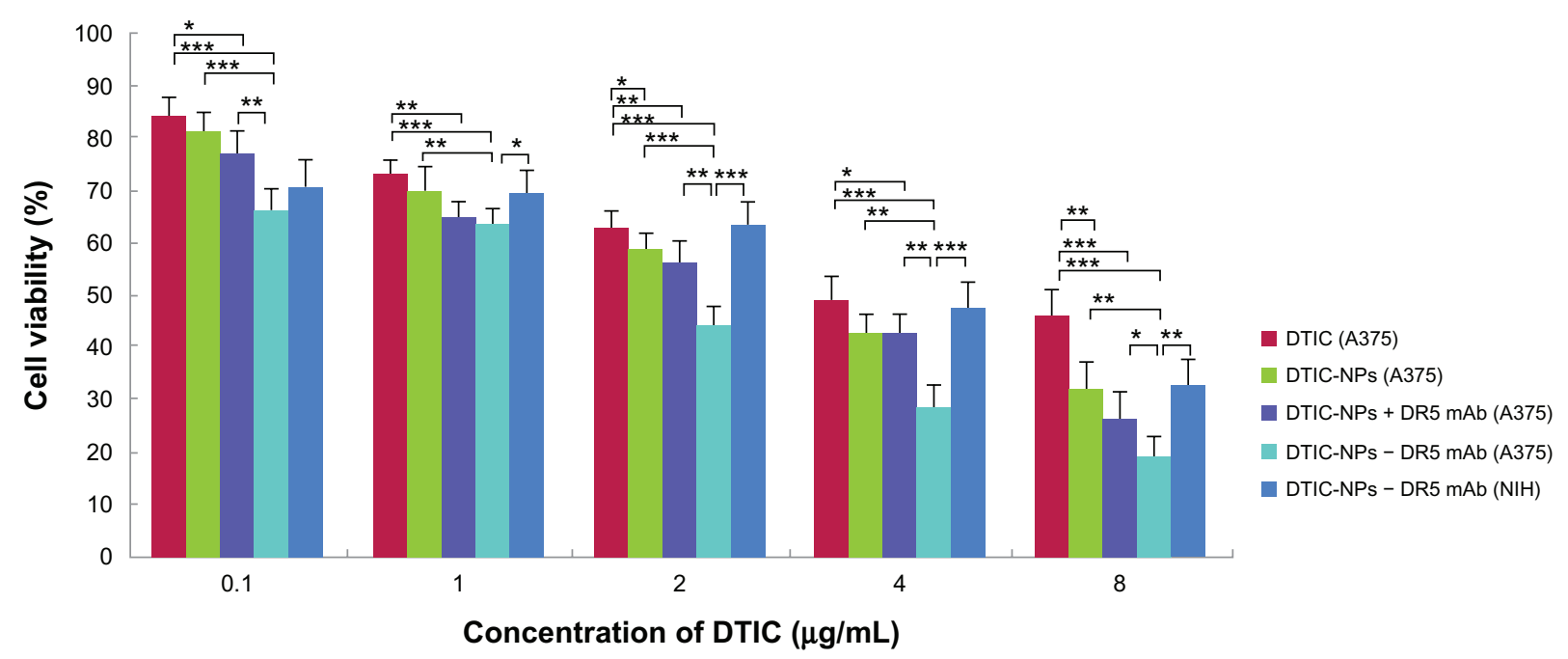

Figure 7 Cytotoxicity of DTIC, DR5 mAb, DTIC-NPs, DTIC-NPs + DR5 mAb, and DTIC-NPs-DR5 mAb in A375 cells and NIH cells. The cells were incubated using different concentrations of DTIC, DR5 mAb, DTIC-NPs, NPs-DR5 mAb, DTIC-NPs + DR5 mAb and DTIC-NPs - DR5 mAb (contain the same DTIC) for a time period of 72 hours (mean \pm standard deviation; $\mathrm{n}=5$ ).

Notes: $* p<0.05$; $* * p<0.01$ I $* * * p<0.001$.

Abbreviations: DTIC, dacarbazine; mAb, monoclonal antibody; NPs, nanoparticles. 


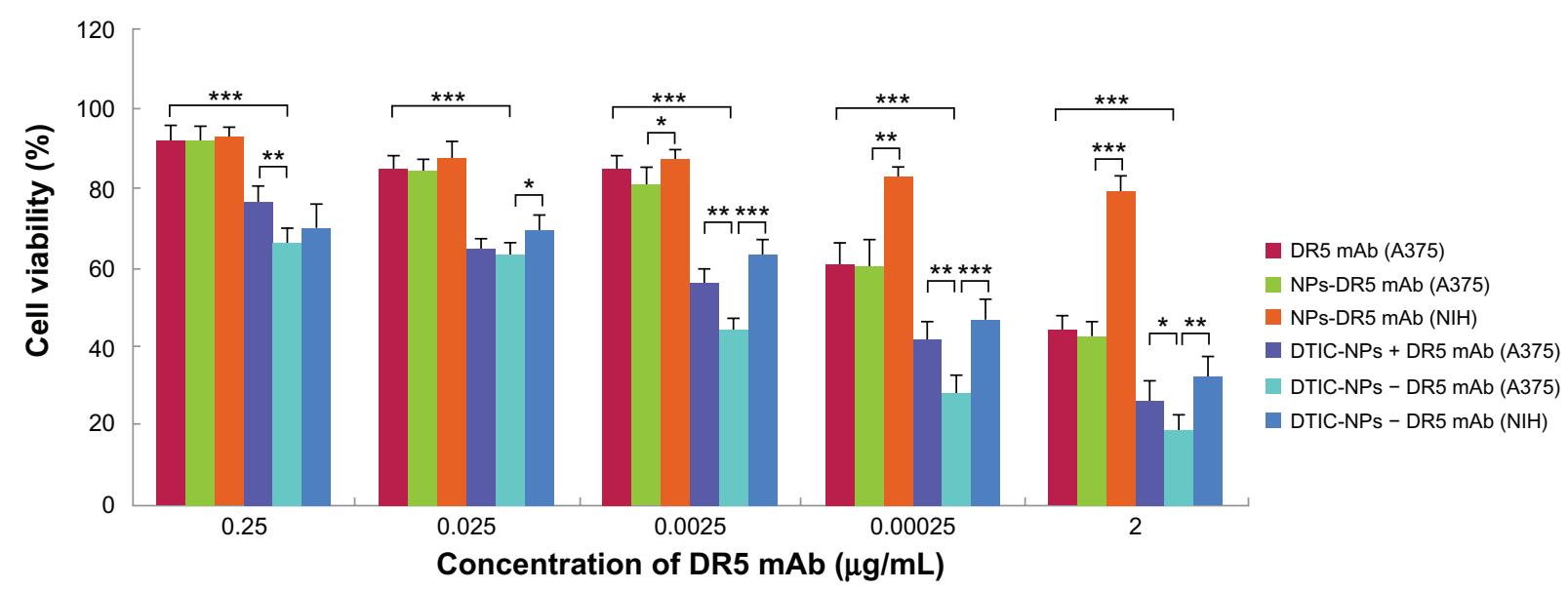

Figure 8 Cytotoxicity of DTIC, DR5 mAb, DTIC-NPs, DTIC-NPs + DR5 mAb, and DTIC-NPs - DR5 mAb in A375 cells or NIH cells. The cells were incubated using different concentrations of DTIC, DR5 mAb, DTIC-NPs, NPs-DR5 mAb, DTIC-NPs + DR5 mAb, and DTIC-NPs - DR5 mAb (contain the same DR5 mAb) for a time period of 72 hours (mean \pm standard deviation; $n=5$ ).

Notes: $* P<0.05$; ** $P<0.01$; $* * * P<0.001$.

Abbreviations: DTIC, dacarbazine; mAb, monoclonal antibody; NPs, nanoparticles.

nanoparticles, indicating that the advanced cytotoxicity of DTIC-DR $5 \mathrm{mAb}$ nanoparticles was also dependent on the conjugated DR5 mAb. ${ }^{38}$ Compared with the other control groups, DTIC-DR5 mAb nanoparticles showed notably enhanced cytotoxicity against DR5-overexpressing cells. Therefore, the combination of specific targeting and drug loading in these nanoparticulate formulations could lead to improved cancer therapy. We speculate that the antitumor mechanism of DTICDR5 mAb nanoparticles is their binding and internalization into tumor cells with subsequent intracellular release of DTIC after PLA degradation.

\section{Cell apoptosis}

Cell apoptosis was evaluated by flow cytometry. Specifically, the A375 cells were treated for 72 hours with free DTIC, free DR5 $\mathrm{mAb}$ or DTIC nanoparticles, DTIC-+DR5 mAb nanoparticles, DTIC + DR5 mAb, as well as DTIC-DR5 mAb nanoparticles containing the same concentration of free DTIC and DR $5 \mathrm{mAb}$. Apoptosis of A375 cells analyzed by FACScan flow cytometry is shown in Figure 9. Figure 10 shows the results of the statistical analysis for average cell apoptosis (\%) induced by the various formulations. The apoptotic cells incubated with free DTIC and $\mathrm{mAb}$ were about $31.7 \% \pm 3.9 \%$ and $24.9 \% \pm 2.1 \%(n=3)$, respectively. In contrast, the number of apoptotic cells increased to about $34.6 \% \pm 4.2 \%$, $39.8 \% \pm 4.1 \%, 44.7 \% \pm 5.6 \%$, and $58.5 \% \pm 5.0 \%(\mathrm{n}=3)$ when the A375 cells were incubated with DTIC nanoparticles, DTIC-DR5 mAb, DTIC-+DR5 mAb nanoparticles, and DTIC-DR5 mAb nanoparticles, respectively. Therefore, a mixture of free DTIC with free mAb or DTIC nanoparticles with free mAb may induce more cancer cell apoptosis when compared with the direct administration of free DTIC and free DR5 $\mathrm{mAb}$, and this is more apparent when the cells were treated with DTIC-DR5 mAb nanoparticles that can bind specifically to DR5-positive A375 cells, which results in enhanced efficiency of intracellular delivery and apoptotic effects of DTIC and DR5 mAb.

\section{Discussion}

The current treatment options for malignant melanoma are still not satisfactory for both patients and clinicians. Singleagent or combination chemotherapy, new agents, or biologic response modifiers alone have not resulted in response rates or durable remissions that are high enough to affect median survival. There is an urgent need to develop new innovative treatment options. Many current opportunities exist for improving the treatment of patients with melanoma, including novel immunotherapy approaches, molecularly targeted treatments, and antiangiogenic therapies. Combinations of these new agents will likely be necessary to make progress in the treatment of the disease. ${ }^{39}$

In this study, we developed a new active targeting drug delivery system (DTIC-DR5 mAb nanoparticles) to combine chemotherapy and active specific immunotherapy in an optimal manner. DTIC is the only chemotherapeutic agent approved by the US Food and Drug Administration for the treatment of melanoma. So far, it is the most active single agent for treatment of metastatic melanoma. ${ }^{40,41}$ Among the existing therapeutic strategies for cancer, targeting the TRAIL pathway has been considered an attractive one in recent years due to its ability to induce apoptosis selectively in malignant cells while demonstrating little cytotoxic- 

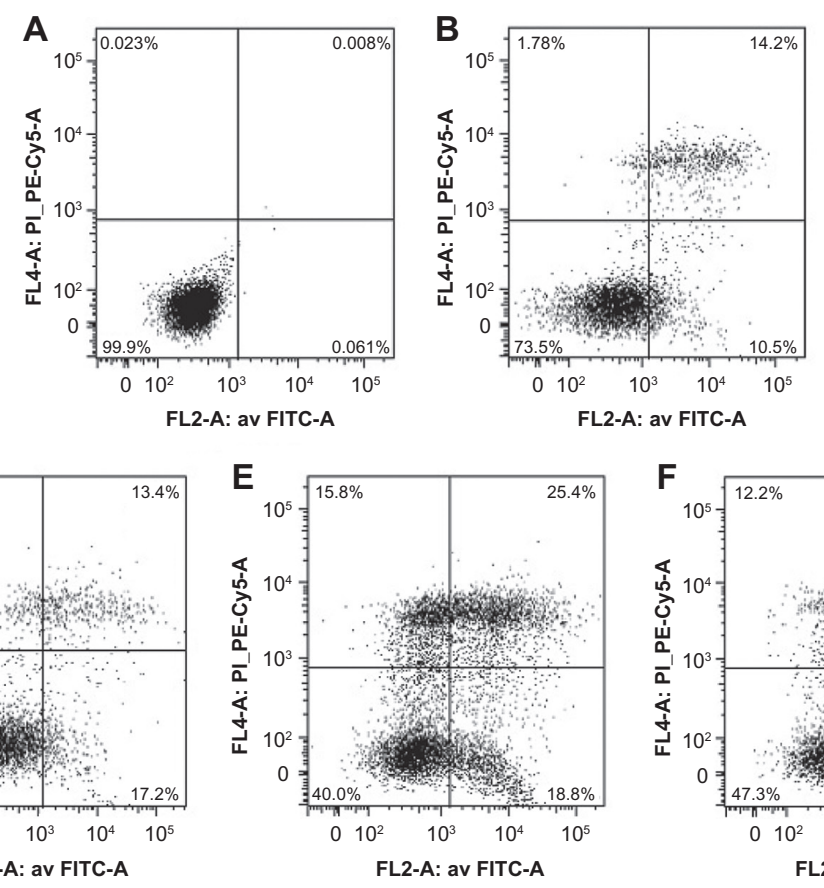
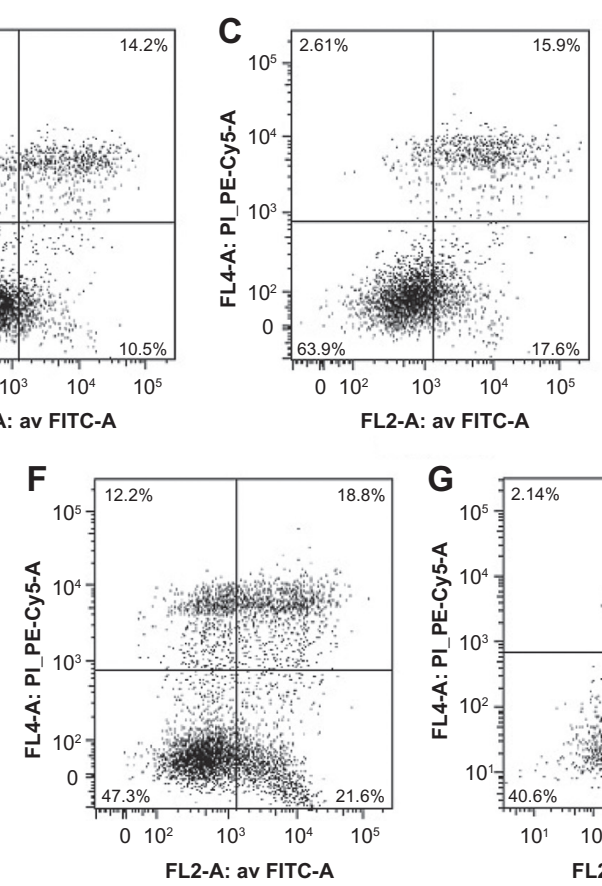

Figure 9 A375 cells apoptosis analyzed by FACScan flow cytometer. (A) Untreated A375 cells were used as controls. (B-G) Pictures are representative results from flow cytometry of propidium iodine and Annexin V-FITC-stained A375 cells treated with free DTIC, free DR5 mAb or DTIC-NPs, DTIC-NPs + DR5 mAb, DTIC + DR5 mAb, DTIC-NPs - DR5 mAb (loaded with the same amount of DTIC and DR5 mAb for 72 hours).

Abbreviations: DTIC, dacarbazine; mAb, monoclonal antibody; NPs, nanoparticles; FITC, fluorescein isothiocyanate.

ity in normal cells. ${ }^{42}$ Early clinical trials have been initiated for the evaluation of mAb to DR4 or DR5, which have been shown to increase the in vitro cytotoxicity of standard chemotherapy drugs and to inhibit tumor growth in vivo in sensitive cell lines. ${ }^{43-45}$ Meanwhile, the difference in the level of DR5 expression between normal cells and tumor cells suggest that DR4 or DR5 mAb can be used as a mediator for targeted drug delivery. Because DR4 or DR5 is abundantly expressed on the surface of malignant melanoma cells, ${ }^{46,47}$ it can be expected that DR4 or DR5 mAb will be very promising bioactive immunotherapeutic molecules in malignant melanoma. Thus, in this research, DTIC, which induces apoptosis through the intrinsic pathway, was used as a model drug to prepare DTICNPs, which were covalently conjugated with highly specific

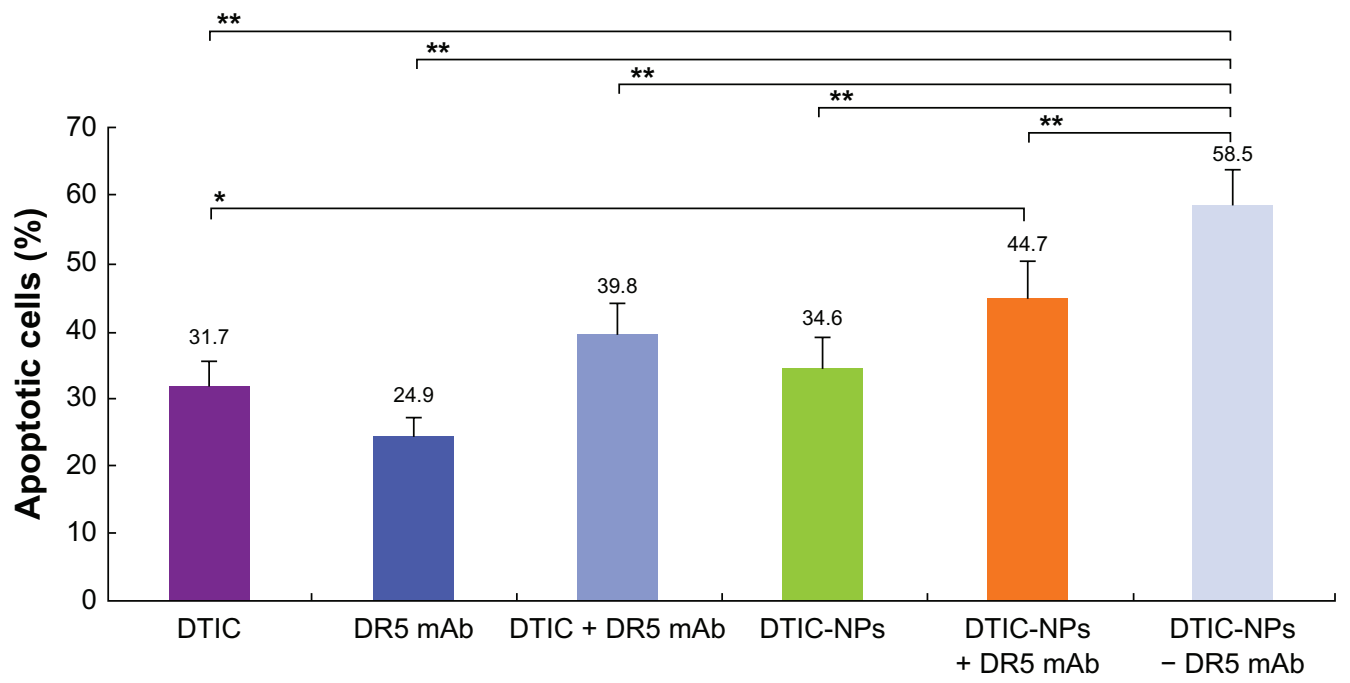

Figure 10 Cell apoptosis (\%) induced by free DTIC, free DR5 mAb, DTIC-NPs, DTIC-NPs+DR5 mAb, DTIC+ DR5 mAb, and DTIC-NPs - DR5 mAb (mean \pm standard deviation; $n=3)$.

Notes: $* P<0.05 ; * * P<0.01$

Abbreviations: DTIC, dacarbazine; mAb, monoclonal antibody; NPs, nanoparticles. 
targeting of functional DR $5 \mathrm{mAb}$ that can contribute directly to apoptosis or growth inhibition of cancer cells through the extrinsic pathway, thereby obtaining an active targeting drug delivery system, ie, DTIC-NPs-DR5 mAb.

In the present work, biodegradable PLA polymers with great compatibility were utilized to prepare DTICNPs using a modified w/o/w double emulsion-solvent evaporation method by ultrasonic processing without any additional additives. Polymerizer encapsulation could enhance the stability of DTIC and decrease its nonspecific toxicity. Furthermore, regulated drug release from the nanoparticles may reduce or eliminate tissue damage on accidental extravasation..$^{20}$ Nanoparticles with a small size of 100-200 $\mathrm{nm}$ are prone to minimizing particle uptake by nontargeted cells, including their premature clearance by the mononuclear phagocytic system, resulting in a long circulation time in vivo. ${ }^{37,48}$ The DTIC-NPs and DTIC-NPsDR5 mAb prepared in this study were sized at about $150 \mathrm{~nm}$ and $170 \mathrm{~nm}$, respectively, which were within the scope of the ideal size between 100 and $200 \mathrm{~nm}$ ) as mentioned above. The antibody conjugation reaction was performed at a low temperature using EDC as the coupling agent, which not only ensures the stability of DR5 $\mathrm{mAb}$ but also preserves the immunoreactivity of DR5 mAb. The DR5 mAb was conjugated onto the surface of the nanoparticles instead of being directly conjugated with DTIC, so the activity of DTIC was also well preserved during preparation. The experimental results demonstrated that DTIC-NPs-DR5 mAb retained their specific binding activity to DR5 and could be almost completely internalized into DR5-overexpressing cells. The superior targeting of DTIC-NPs-DR5 mAb was attributed to more cellular uptake by tumor cells, which was mediated by ligand-receptor recognition.

The results demonstrated that the DTIC-NPs-DR5 mAb had improved antitumor activity, increased cell apoptosis in DR5-positive malignant melanoma cells, and minimal toxicity to DR5-negative cells. The mechanism by which the effective antitumor activity of DTIC-NPs-DR5 mAb can be achieved might also contribute to the three-phase delivery of the targeted nanoparticles. In the first phase, the nanoparticles slowly accumulate in tumor cells, ultimately reaching high tumor levels due to the enhanced permeability and retention effect. ${ }^{20}$ In the second phase, the targeted nanoparticle binding and internalization into tumor cells might be associated with DR5 mAb on the surface of the nanoparticles, which initiates receptor-mediated endocytosis by binding to DR5 in the cell membrane and then the loaded DTIC is released to kill cells. ${ }^{49}$ In the third phase, the DR5 mAb exhibits bispecific properties of selectively binding to DR5-positive cancer cells and inducing apoptosis of cancer cells through the extrinsic pathway. DTIC and $\mathrm{DR} 5 \mathrm{mAb}$ in the active targeting delivery system induce apoptosis of cancer cells through the intrinsic pathway and the extrinsic pathway, respectively, and may increase the sensitivity of cancer cells to the cytotoxic effects of the chemical drug as well as the antibody. Thus, not only free DR5 mAb but also DR5 mAb-modified drug-loaded nanoparticles could have a role in tumor therapy.

\section{Conclusion}

The present study describes a new therapeutic strategy of chemotherapy and immunotherapy for malignant melanoma. Modified DTIC-loaded PLA nanoparticles mediated by DR5 mAb were successfully prepared and evaluated in detail. For the first time, we used biodegradable PLA polymers to develop small-sized DTIC nanoparticles and conjugated targeted ligand DR5 mAb, which has anticancer biological activity itself, onto the surface of nanoparticles via conjugation to form antibody-modified nanoparticles. In vitro experiments demonstrated that the DTIC-NPs-DR5 mAb drug targeting system can specifically target DR5overexpressing malignant melanoma cells and become internalized efficiently. Most strikingly, compared with conventional DTIC-NPs, DTIC-NPs-DR5 mAb show significantly enhanced antitumor activity, increased cancer cell apoptosis, and decreased nonspecific toxicity.

These results suggest that DTIC-NPs-DR5 mAb could be used as an efficient targeted delivery system. This new chemoimmunotherapeutic approach might be a valuable treatment for DR5-overexpressing malignant melanoma with fewer side effects than conventional cytotoxins. The outcome of such chemoimmunotherapy is profound because the use of the antibody directly contributes to the inhibition of cell growth and cell death. It is conceivable that this novel nanotechnology could be applied to other cytotoxins.

\section{Acknowledgments}

We acknowledge the financial support of the National Natural Science Foundation (30973459 and 81072100), Nanotechnology Foundation of Shanghai Science and Technology Committee (0952nm02800), Science and technology projects of Jiaxing (2010AY1062).

\section{Disclosure}

The authors report no conflicts of interest in this work. 


\section{References}

1. Berwick M, Erdei E, Hay J. Melanoma epidemiology and public health. Dermatol Clin. 2009;27(2):205-214, viii.

2. Agarwala SS, O'Day SJ. Current and future adjuvant immunotherapies for melanoma: Blockade of cytotoxic T-lymphocyte antigen-4 as a novel approach. Cancer Treat Rev. 2011;37(2):133-142.

3. Lens MB, Dawes M. Global perspectives of contemporary epidemiological trends of cutaneous malignant melanoma. $\mathrm{Br} J$ Dermatol. 2004;150(2):179-185.

4. Balch MH, Reintgen DS, Kirkwood JM, Houghton A. Cutaneous melanoma. In: De Vita VT, Hellman S, Rosenberg SA, editors. Cancer: Principles and Practice of Oncology. 5th ed. Philadelphia, PA: JB Lippincott; 1997.

5. Soengas MS, Lowe SW. Apoptosis and melanoma chemoresistance. Oncogene. 2003;19;22(20):3138-3151.

6. Fecher LA, Cummings SD, Keefe MJ, Alani RM. Toward a molecular classification of melanoma. J Clin Oncol. 2007;25(12):1606-1620.

7. Postovit LM, Seftor EA, Seftor RE, Hendrix MJ. Targeting nodal in malignant melanoma cells. Expert Opin Ther Targets. 2007;11(4):497-505.

8. Markovic SN, Erickson LA, Rao RD, et al; Melanoma Study Group of Mayo Clinic Cancer Center. Malignant melanoma in the 21st century, part 2: staging, prognosis, and treatment. Mayo Clin Proc. 2007;82(4):490-513.

9. La Porta CA. Drug resistance in melanoma: New perspectives. Curr Med Chem. 2007;14(4):387-391.

10. McNulty SE, del Rosario R, Cen D, Meyskens FL Jr, Yang S. Comparative expression of NFkappaB proteins in melanocytes of normal skin vs benign intradermal naevus and human metastatic melanoma biopsies. Pigment Cell Res. 2004;17(2):173-180.

11. Chen J, Wu H, Han D, Xie C. Using anti-VEGF McAb and magnetic nanoparticles as double-targeting vector for the radioimmunotherapy of liver cancer. Cancer Lett. 2006;231(2):169-175.

12. Li JL, Wang L, Liu XY, et al. In vitro cancer cell imaging and therapy using transferrin-conjugated gold nanoparticles. Cancer Lett. 2009;274(2):319-326

13. Cho K, Wang X, Nie S, Chen ZG, Shin DM. Therapeutic nanoparticles for drug delivery in cancer. Clin Cancer Res. 2008;14(5):1310-1316.

14. Gref R, Minamitake Y, Peracchia MT, Trubetskoy V, Torchilin V, Langer R. Biodegradable long-circulating polymeric nanospheres. Science. 1994;263(5153):1600-1603.

15. Zhang QZ, Zha LS, Zhang Y, et al. The brain targeting efficiency following nasally applied MPEG-PLA nanoparticles in rats. J Drug Target. 2006;14(5):281-290.

16. Dong Y, Feng SS. Methoxy poly(ethylene glycol)-poly(lactide) (MPEG-PLA) nanoparticles for controlled delivery of anticancer drugs. Biomaterials. 2004;25(14):2843-2849.

17. Lu W, Zhang Y, Tan YZ, Hu KL, Jiang XG, Fu SK. Cationic albuminconjugated pegylated nanoparticles as novel drug carrier for brain delivery. J Control Release. 2005;107(3):428-448.

18. Rapoport N. Physical stimuli-responsive polymeric micelles for anticancer drug delivery. Prog Polym Sci. 2007;32:962-990.

19. Kim TY, Kim DW, Chung JY, et al. Phase I and pharmacokinetic study of Genexol-PM, a cremophor-free, polymeric micelle-formulated paclitaxel, in patients with advanced malignancies. Clin Cancer Res. 2004;10(11):3708-3716.

20. Allen TM, Cullis PR. Drug delivery systems: Entering the mainstream. Science. 2004;303(5665):1818-1822.

21. Stayton PS, Hoffman AS, Murthy N, et al. Molecular engineering of proteins and polymers for targeting and intracellular delivery of therapeutics. J Control Release. 2000;65(1-2):203-220.

22. Wartlick H, Michaelis K, Balthasar S, Strebhardt K, Kreuter J, Langer K. Highly specific HER2-mediated cellular uptake of antibody-modified nanoparticles in tumour cells. J Drug Target. 2004;12(7):461-471.

23. Anhorn MG, Wagner S, Kreuter J, Langer K, von Briesen H. Specific targeting of HER 2 overexpressing breast cancer cells with doxorubicinloaded trastuzumab-modified human serum albumin nanoparticles. Bioconjug Chem. 2008;19(12):2321-2331.
24. Mitra A, Coleman T, Borgman M, Nan A, Ghandehari H, Line BR. Polymeric conjugates of mono- and bi-cyclic alphaVbeta 3 binding peptides for tumor targeting. J Control Release. 2006;114(2):175-183.

25. Xiong XB, Huang Y, Lu WL, et al. Enhanced intracellular delivery and improved antitumor efficacy of doxorubicin by sterically stabilized liposomes modified with a synthetic RGD mimetic. J Control Release. 2005;107(2):262-275.

26. Adams GP, Weiner LM. Monoclonal antibody therapy of cancer. Nat Biotechnol. 2005;23(9):1147-1157.

27. Walczak H, Miller RE, Ariail K, et al. Tumoricidal activity of tumor necrosis factor-related apoptosis-inducing ligand in vivo. Nat Med. 1999;5(2):157-163.

28. Evdokiou A, Bouralexis S, Atkins GJ, et al. Chemotherapeutic agents sensitize osteogenic sarcoma cells, but not normal human bone cells, to Apo2L/TRAIL-induced apoptosis. Int $J$ Cancer. 2002;99(4):491-504.

29. LeBlanc HN, Ashkenazi A. Apo2L/TRAIL and its death and decoy receptors. Cell Death Differ. 2003;10(1):66-75.

30. Chuntharapai A, Dodge K, Grimmer K, et al. Isotype-dependent inhibition of tumor growth in vivo by monoclonal antibodies to death receptor 4. J Immunol. 2001;166(8):4891-4898.

31. Ichikawa K, Liu W, Zhao L, et al. Tumoricidal activity of a novel antihuman DR5 monoclonal antibody without hepatocyte cytotoxicity. Nat Med. 2001;7(8):954-960.

32. Cretney E, Takeda K, Smyth MJ. Cancer: Novel therapeutic strategies that exploit the TNF-related apoptosis-inducing ligand (TRAIL)/TRAIL receptor pathway. Int J Biochem Cell Biol. 2007;39(2):280-286.

33. Georgakis GV, Li Y, Humphreys R, et al. Activity of selective fully human agonistic antibodies to the TRAIL death receptors TRAIL-R1 and TRAIL-R2 in primary and cultured lymphoma cells: Induction of apoptosis and enhancement of doxorubicin- and bortezomib-induced cell death. Br J Haematol. 2005;130(4):501-510.

34. Lu W, Zhang Y, Tan YZ, Hu KL, Jiang XG, Fu SK. Cationic albuminconjugated pegylated nanoparticles as novel drug carrier for brain delivery. J Control Release. 2005;107(3):428-448.

35. Kocbek P, Obermajer N, Cegnar M, Kos J, Kristl J. Targeting cancer cells using PLGA nanoparticles surface modified with monoclonal antibody. J Control Release. 2007;120(1-2):18-26.

36. Wang H, Song S, Kou G, et al. Treatment of hepatocellular carcinoma in a mouse xenograft model with an immunotoxin which is engineered to eliminate vascular leak syndrome. Cancer Immunol Immunother. 2007;56(11):1775-1783.

37. Brigger I, Dubernet C, Couvreur P. Nanoparticles in cancer therapy and diagnosis. Adv Drug Deliv Rev. 2002;54(5):631-651.

38. MoY, Lim LY. Preparation and in vitro anticancer activity of wheat germ agglutinin (WGA)-conjugated PLGA nanoparticles loaded with paclitaxel and isopropyl myristate. $J$ Control Release. 2005;107(1):30-42.

39. Mouawad R, Sebert M, Michels J, Bloch J, Spano JP, Khayat D. Treatment for metastatic malignant melanoma: Old drugs and new strategies. Crit Rev Oncol Hematol. 2010;74(1):27-39.

40. Quirin C, Mainka A, Hesse A, Nettelbeck DM. Combining adenoviral oncolysis with temozolomide improves cell killing of melanoma cells. Int J Cancer. 2007;121(12):2801-2807.

41. Lillehammer T, Engesaeter BO, Prasmickaite L, Maelandsmo GM, Fodstad O, Engebraaten O. Combined treatment with Ad-hTRAIL and DTIC or SAHA is associated with increased mitochondrial-mediated apoptosis in human melanoma cell lines. J Gene Med. 2007;9(6):440-451.

42. de Bruyn M, Bremer E, Helfrich W. Antibody-based fusion proteins to target death receptors in cancer. Cancer Lett. January 5, 2011. [Epub ahead of print.]

43. Motoki K, Mori E, Matsumoto A, et al. Enhanced apoptosis and tumor regression induced by a direct agonist antibody to tumor necrosis factor-related apoptosis-inducing ligand receptor 2. Clin Cancer Res. 2005;11:3126-3135.

44. Pukac L, Kanakaraj P, Humphreys R, et al. HGS-ETR1, a fully human TRAIL-receptor 1 monoclonal antibody, induces cell death in multiple tumour types in vitro and in vivo. Br J Cancer. 2005;92:1430-1441. 
45. Duiker EW, Mom CH, de Jong S, et al. The clinical trail of TRAIL. Eur $J$ Cancer. 2006;42(14):2233-2240.

46. Zhang XD, Franco AV, Nguyen T, Gray CP, Hersey P. Differential localization and regulation of death and decoy receptors for TNFrelated apoptosis-inducing ligand (TRAIL) in human melanoma cells. J Immunol. 2000;164(8):3961-3970.

47. Nguyen T, Thomas W, Zhang XD, Gray C, Hersey P. Immunologically-mediated tumour cell apoptosis: The role of TRAIL in T cell and cytokine-mediated responses to melanoma. Forum (Genova). 2000;10(3):243-252.
48. Visaria RK, Griffin RJ, Williams BW, et al. Enhancement of tumor thermal therapy using gold nanoparticle-assisted tumor necrosis factoralpha delivery. Mol Cancer Ther. 2006;5(4):1014-1020.

49. Mamot C, Drummond DC, Noble CO, et al. Epidermal growth factor receptor-targeted immunoliposomes significantly enhance the efficacy of multiple anticancer drugs in vivo. Cancer Res. 2005;65(24):11631-11638.
International Journal of Nanomedicine

\section{Publish your work in this journal}

The International Journal of Nanomedicine is an international, peerreviewed journal focusing on the application of nanotechnology in diagnostics, therapeutics, and drug delivery systems throughout the biomedical field. This journal is indexed on PubMed Central, MedLine, CAS, SciSearch ${ }^{\circledR}$, Current Contents ${ }^{\circledR} /$ Clinical Medicine,

\section{Dovepress}

Journal Citation Reports/Science Edition, EMBase, Scopus and the Elsevier Bibliographic databases. The manuscript management system is completely online and includes a very quick and fair peer-review system, which is all easy to use. Visit http://www.dovepress.com/ testimonials.php to read real quotes from published authors.

Submit your manuscript here: http://www.dovepress.com/international-journal-of-nanomedicine-journal 